\title{
DIREITOS FUNDAMENTAIS DOS MORADORES DE RUA NOS CENTROS URBANOS
}

\author{
Reginaldo dos Santos Gomes* \\ Professora Mestre Aline Stangorlini**
}

\section{RESUMO}

Os moradores de rua fazem parte de um grupo vulnerável, com tendência de crescimento exponencial nos últimos anos devido ao prolongamento da crise econômica da última década. Verifica-se nesse texto que entes políticos e a sociedade civil se organizam para trazer alento para essa população e diminuir os impactos da discriminação. Os estudos mostram que o problema é complexo, tendo em vista o caráter heterogêneo dos vulneráveis, exigindo da sociedade e do poder público avaliações individuais em respeito à peculiaridade de cada caso .Os especialistas afirmam que a questão deve ser analisada de maneira interdisciplinar, de modo que envolvam psicólogos, assistentes sociais, outros profissionais da saúde, bem como os operadores do direito, pois estes últimos lidam diretamente com a aplicação constitucional da dignidade da pessoa humana. Infere-se que o alcance da constituição e das legislações extravagantes já ecoam, mesmo que timidamente, com o objetivo de agasalhar aqueles que, literalmente, vivem nas ruas. Nota-se na pesquisa que a jurisprudência moderna traz reflexões importantes para esse debate, pois ao sustentar que não se devem fazer desapropriações em tempos pandêmicos e que morador de rua tem direito igual a qualquer outro cidadão, os julgadores aplicam o princípio da igualdade material, como também expõem a política de exclusão social existente no Brasil.

Palavras-chave: morador de rua; Vulnerabilidade; Direito Fundamental; Exclusão; Discriminação.

\section{FUNDAMENTAL RIGHTS OF HOMELESS PEOPLE IN URBAN CENTERS.}

\section{ABSTRACT}

Homeless people are part of a vulnerable group, with an exponential growth trend in recent years due to the prolongation of the economic crisis of the last decade. It can be seen in this text that political entities and civil society organize themselves to bring encouragement to this population and reduce the impacts of discrimination. Studies show that the problem is complex, in view of the heterogeneous character of the vulnerable, requiring individual assessments from society and public authorities in respect of the peculiarity of

* Graduado em Direito pela Universidade Metodista de São Paulo.

E-mail reginaldok2008@hotmail.com

** Mestre em Direito civil comparado pela Pontifícia Universidade Católica/PUC. 
each case. involving psychologists, social workers, other health professionals, as well as legal operators, since the latter deal directly with the constitutional application of the dignity of the human person. It is inferred that the scope of the constitution and extravagant legislation are already echoing, albeit timidly, with the aim of wrapping up those who literally live on the streets. It is noted in the research that modern jurisprudence brings important reflections to this debate, since by maintaining that expropriations should not be made in pandemic times and that homeless people have the right to equal any other citizen, the judges apply the principle of material equality, as well as exposing the existing social exclusion policy in Brazil.

Keywords: homeless person; Vulnerability; Fundamental Right; Exclusion; Discrimination.

\section{INTRODUÇÃO}

As constantes transformações sociais e econômicas enfrentadas pelo Brasil nos últimos anos têm feito crescer consideravelmente a população de rua. Esse cenário já é desafio de parte das políticas públicas das assistências sociais de todos os governos nos grandes centros urbanos.

Nesse contexto, este trabalho visa trazer não só a visão comunitária, mas também a análise jurídica prática da vivência diária nas ruas, sob a ótica dos Direitos fundamentais, sem desprezar o panorama histórico que fez a população de rua crescer.

Isso porque se é papel do cientista social analisar as causas das mazelas que acometem a sociedade, é dever do jurista não só observar os fenômenos sociais, mas buscar mitigá-los, conforme prescreve o Código de Ética e disciplina da OAB no seu artigo Art. 30: "o advogado deve ter consciência de que o Direito é um meio de mitigar as desigualdades para o encontro de soluções justas e que a lei é um instrumento para garantir a igualdade de todos". (BRASIL, RESOLUÇÃO N. 02/2015)

Assim, ao tratar desse tema, a pesquisa em questão, debruça-se sobre o conceito de direitos fundamentais, trazendo à tona a importância de uma legislação inclusiva, capaz de oferecer oportunidades a todas as pessoas sem distinção de classe.

Dessa forma, o presente texto tem como tema os direitos fundamentais dos moradores de ruas nos centros urbanos, apresentado numa abordagem crítica, tendo como referencial as teses de juristas, sociólogos renomados, filósofos, religiosos e historiadores, sem desconsiderar a percepção das pessoas que vivem nessas condições

\section{ESCRAVIDÃO, DESIGUALDADE E DEMOCRACIA}

A situação dos moradores de rua em cada país pode ter um retrato ou causa diferente. Em regiões de pouca desigualdade e com sistema de bem-estar social robusto, como na Europa ocidental, percebe-se que fatores ligados a imigração e problemas mentais são fatores preponderantes para levar alguém à marginalização, e não necessariamente problemas financeiros. 
Por outro lado, nos países latino-americanos, como o Brasil, carregados de problemas estruturais desde o descobrimento, pode-se afirmar que boa parte da população que vive na rua é fruto da desorganização política, caracterizada pela ausência do Estado nos que diz respeito à educação e distribuição de renda.

Assim, nesses países, historicamente, os direitos de primeira, segunda e terceira geração foram implementados de forma tardia. Por exemplo, enquanto Estados Unidos e Europa cessavam a escravidão, o Brasil manteve essa prática por décadas.

Outro dado importante a se considerar foi que o ocidente experimentou um processo de democratização após a segunda guerra bem diferente de Brasil, Chile e Argentina, países marcados por longas ditaduras recentes. Nesse contexto, a implementação de políticas que reduzissem a desigualdade foi prejudicada pela falta de transparência que regiam esses sistemas totalitários.

Quando a escravidão foi abolida no Brasil, em 13 de maio de 1888, através da lei áurea, marcou definitivamente a história dos direitos humanos no país. Isso porque tal período obscuro da nação, com a consequente libertação dos escravos, gerou impactos econômicos, morais, sociais e jurídicos cujos efeitos são sentidos atualmente.

Nesse sentido, considerando as observações de Gilberto Freyre, as casas grandes expressaram a concepção que um país tem de povo, revelando a continuidade do caráter social brasileiro. (FREYRE, 2006.)

Não se pode dizer que toda origem da miséria é oriunda da escravidão. Por outro lado, existem fartas evidências de que a maneira como ela foi tratada pelo poder constituído à época foi determinante para acelerar o processo de marginalização de boa parcela da população, uma vez que muitos foram privados de uma vida digna, durante e pós libertação.

Por isso, quando se observa os 300 anos que antecederam a abolição da escravatura, nota-se gerações inteiras sendo doutrinadas a conceber a atividade econômica baseada na mão-de-obra escrava, principalmente da população negra capturada na África, cujos descendentes tiveram a mesma sorte.

Ainda, observa-se que a indignação dos poderosos desse período consistia na preocupação com o esquema econômico e não com o destino dos recém libertos, conforme descreve o historiador Boris Fausto:

Quanto à abolição, as iniciativas do imperador de extinguir gradualmente o sistema escravista provocaram fortes ressentimentos entre os proprietários rurais, e não só entre eles. Os fazendeiros de café do vale do paraíba desiludiram-se do império, do qual esperavam uma atitude de defesa de seus interesses. Com isso, o regime perdeu sua principal base social de apoio. (FAUSTO,2018. p. 133)

Com o fim do modelo escravocrata, os imigrantes europeus substituíram parte do trabalho exercido pelos escravos, e esses últimos ficaram à mercê da própria sorte no extrato social.

Ainda, o Estado, em sua visão patriarcal, não se preocupou em dispensar aos libertos uma política de reintegração social, levando milhares de pessoas a con- 
dições subalternas, muitos deles trabalhando, mas recebendo salários irrisórios e moradias precárias.

Perceptível é a forma como a marginalização se intensificava nas cidades e no campo, enquanto os grandes proprietários, protegidos pelo poder público, garantiam suas mordomias, as quais eram hereditariamente mantidas. Nesse mesmo sentido, Darcy Ribeiro assevera:

\begin{abstract}
Não é por acaso, pois, que o Brasil passa de colônia a nação independente e de Monarquia a República, sem que a ordem fazendeira seja afetada e sem que o povo perceba. Todas as nossas instituições políticas constituem a superfetação de um poder efetivo que se mantém intocado: o poderio do patronato fazendeiro. (RIBEIRO, 2006. p. 201)
\end{abstract}

Dessa forma, construiu-se um novo modelo de perpetuar pobreza, concentrando nas mãos dos grandes latifundiários a riqueza em detrimento da nova classe social que emergia.

Atualmente, pode-se afirmar que a sociedade brasileira, embora transformada e informada pela pós-modernidade, ainda sustenta resquícios desse sistema que infla e marginaliza os seres humanos. Se outrora a concentração de riqueza ficava nas mãos de poucos fazendeiros, agora são os banqueiros, os donos de grandes mídias e multe empresários que condensam grandes fortunas.

Para se ter uma ideia, em dezembro de 2019, o Brasil tinha a segunda pior concentração de renda do mundo, segundo relatório da ONU, reportado pelo portal G1. Assim, os 10 por cento mais ricos concentram mais 40 por cento da renda total do país. $(\mathrm{G} 1,2019)$

Assim, no plano econômico, a miserabilidade que impera no Brasil, manifestada na população de rua, bem como em parte da sociedade, é a manifestação de uma visão perpetrada há séculos, cuja sistema democrático não foi capaz de romper.

Nesse contexto é importante observar a dinâmica histórica em que a identidade brasileira foi desenvolvida, tornando-se desafio ao legislador construir uma sociedade justa e igualitária, conforme prescrito na Carta Maior, nos ditames do estado democrático de direito.

Constata-se, dessa forma, que a democracia não combina com desigualdade, uma vez que um de seus pressupostos é a liberdade, pelo que o homem livre deve usufruir seus direitos em iguais condições com qualquer outro cidadão, através do princípio da isonomia.

Sabe-se, porém, que a democracia não fora o regime preferido daqueles que governavam, sendo malvista pela classe privilegiada. Exemplo disso é o que acontecia na idade média, em que os camponeses não tinham os mesmos direitos da realeza, dos clérigos e dos nobres.

Percebe-se o pilar dessa concepção medieval no filósofo grego Platão, o qual denominava a democracia como regime inferior, capaz de levar à tirania, conforme descrito em seu livro "A República". É evidente que os tiranos deturparam a ideia platônica de aristocracia, encontrando nela base perfeita para disseminar o totalitarismo. (PLATÃO, 2007) 
Com o surgimento do iluminismo e das revoluções subsequentes, implementou-se uma nova visão de mundo, em que o homem seria o fim de todas as coisas. Nessa esteira vieram a revolução francesa e industrial, iniciando uma nova fase de direitos e reivindicações, na tentativa de garantir direitos básicos a todos os cidadãos e não mais a certos grupos, fazendo emergir uma nova classe denominada de burguesia.

Para que essas garantias fossem efetivadas era preciso acabar com o monopólio político e implantar a democracia a partir de uma constituição prescritiva de direitos.

Assim sendo, a democracia brasileira ganhou seu ápice com a constituição federal de 1988, estabelecendo-se o regime democrático de direito, ou seja, após décadas oscilando entre regimes diferentes, construiu-se na sociedade, representada pelo parlamento, aquilo que é considerada uma das constituições mais modernas e ampla em direitos que existem.

Foram muitos os direitos concebidos na Carta Magna, que Pedro Lenza assim assevera: "Como se sabe, depois de tanto trabalho e dificuldades, a constituição de 1988 foi promulgada em 5 de outubro, redemocratizado o país, com importantes avanços".

Com isso, os direitos fundamentais ganharam uma nova roupagem, tendo em vista a eficácia imediata e programática da Carta maior, conforme afirma, em artigo publicado, Ana Paula Motta Costa

Esse panorama começou a alterar-se a partir do final da década de 1980 e início dos anos noventa com a Constituição Federal de 1988, que considerou os direitos sociais como direitos fundamentais de todo cidadão, e com a Lei Orgânica da Assistência Social (LOAS), que regulamentou os artigos 203 e 204 da Constituição Federal, reconhecendo a Assistência Social como política pública. (COSTA, 2005, p. 6).

Apesar desses avanços, fica nítida a incongruência quando se trata do poder aquisitivo das pessoas, evidenciando que a população de baixa renda é prejudicada com a falta de acesso à justiça, educação e moradia. Nesse cenário, é perceptível que a desigualdade atinge todos os aspectos da vida do pobre, o qual se tiver um teto, privar-se-á do básico para uma vida digna, caso não o tenha, viverá pelas ruas e pontes em busca de abrigo. Nesse sentido, Fernando Tadeu Davi afirma:

A igualdade buscada pelas pessoas é aquela em que tenham garantidos os mínimos direitos que a constituição brasileira prescreve e em seus primeiros artigos. Ser igual perante a lei é termos todos direito à casa, direito ao Trabalho, direito à saúde, direitos ao transporte digno, sem atropelos e com preços compatíveis, direito à segurança sem ameaças e torturas e nem discriminação por questões raciais, direito ao lazer, direito ao teatro, direito ao acesso universal e igualitário à justiça e tantos outros direitos que poucos tem respeitados. E a população em situação de rua, como fica frente ao leque de direitos que lhe são negados? Onde estará a tão propalada garantia e efetividade? Onde está a dignidade? Onde está a lei? (TADEU, 2019, p. 359) 
Constata-se que a democracia consagrada na Constituição, passados mais de 30 anos, ainda não conseguiu eliminar aquilo que o constituinte buscou combater, isto é, a diminuição da desigualdade em todas as suas formas, pois faltou, na prática, a efetivação da igualdade formal e material. A primeira, diz respeito ao tratamento que a lei prescreve a todas as pessoas, enquanto a segunda é a maneira especial de lidar, isonomicamente, com os mais fracos.

Nesse sentido pontifica o constitucionalista André Ramos Tavares

A primeira afirmação a ser feita aqui é a de que os tratamentos diferenciados podem estar em plena consonância com a Constituição. É que a igualdade implica o tratamento desigual das situações de vida desiguais, na medida de sua desigualação. Aliás, trata-se de exigência contida no próprio princípio da Justiça. (TAVARES,2020, p. 577)

A questão que fica é a possibilidade de a democracia brasileira encontrar meios para romper a desigualdade social, principalmente quando observada a inércia dos entes públicos. Os últimos 30 anos provaram que a corrupção, a burocracia, o lobby político e a falta de vontade de cessar com os privilégios são entraves a que se chegue à diminuição da pobreza.

Salienta-se que o Brasil, conforme descrito no artigo $3^{\circ}$ da Constituição (BRASIL, 1988), tem como objetivo fundamental erradicar a pobreza e a marginalização e reduzir as desigualdades sociais e regionais. A efetivação desse princípio não se realizará sem a participação dos três poderes, isto é, legislativo, executivo e judiciário, uma vez que são eles os responsáveis por criar, executar e fazer valer os princípios constitucionais.

Fora raras exceções, não se tem visto uma coordenação nacional capaz de unir forças contra o combate à marginalização. Pelo contrário, são as entidades da sociedade civil, como igrejas, associações e ONGs que se organizam para minorar o sofrimento dos necessitados.

Assim, tratar desigualmente os desiguais é fornecer políticas públicas adequadas à população mais pobre, em que os entes públicos e a sociedade cooperem juntos para dirimir a vulnerabilidade social, seja com ações diretas, seja por meio de uma legislação inclusiva.

Nesse sentido, já em 2008, antecipando ao que se vive hoje, o Ministério Público do Distrito Federal lançou a "cartilha dos moradores em situação de rua", que visa direcionar os atores públicos a atender, de forma personalíssima e transformadora, especialmente esse público. O texto desafiador, já na apresentação afirma:

O Ministério Público do Distrito Federal e Territórios (MPDFT) e a sociedade civil acompanham a prestação de serviços públicos às pessoas em situação de rua e buscam estimular a capacitação continuada dos agentes públicos. Esta cartilha tem por objetivo orientar e sensibilizar todos os colaboradores envolvidos com essa temática, em especial servidores e agentes públicos do Distrito Federal, para uma atuação que 
promova a transformação desse contexto atual das pessoas em situação de rua, de forma acolhedora e livre de preconceitos, reconhecendo o indivíduo como agente atuante da própria história. (MPDFT: 2018. p, 4)

Nota-se que a ação da sociedade e dos servidores deve ir além do pragmatismo assistencial, proporcionando às pessoas marginalizadas condições de transformação e inclusão. Para isso o acolhimento e o reconhecimento das liberdades individuais, bem como firmar a igualdade como princípio inegociável são primordiais, conforme destaca o texto supracitado.

Ressalta-se, assim, que implementar diretrizes para combater a desigualdade não é apenas uma política de governo, e sim de Estado, conforme prescreve a constituição no artigo 23: "É competência comum da União, dos Estados, do Distrito Federal e dos Municípios: X - combater as causas da pobreza e os fatores de marginalização, promovendo a integração social dos setores desfavorecidos". (BRASIL, 2020)

\section{ORIGEM E PERFIL DO MORADOR DE RUA}

Antes da industrialização, era comum observar a perambulação de uma figura folclórica, maltrapilha, gentil, que acenava às pessoas, tratada com certo respeito, recebia ajuda e abrigo da comunidade, sorria para as pessoas e interagiam com elas, surgia e ressurgia de tempos em tempos, sendo aceito por todos. Essa era a situação do morador de rua em meados do século passado, conforme pontuado por Amauri Meireles. (2019).

Com o passar dos anos, no entanto, muda o retrato do morador de rua, não sendo ele visto mais como integrante da comunidade, pelo contrário, um estorvo ou escória, sendo tratado com total desrespeito sobre o aspecto dos direitos humanos, de modo que as políticas públicas atuais não observam sua heterogeneidade marcada por problemas diversos e complexos.

Nesse contexto, a origem da população de rua no Brasil deve ser analisada sob dois ângulos. O primeiro, mais amplo, refere-se à dinâmica social e econômica que transformou o país em meados do século passado, sobretudo no período denominado de milagre econômico. Em segundo lugar, é mister observar os traços individuais, uma vez que as particularidades dessa população não se mostraram homogêneas.

Essas duas considerações mostram que o surgimento da população de rua é considerado um fenômeno social, uma vez que o desenvolvimento urbano não acompanhou os níveis de infraestrutura necessária para atender a todos, fazendo com que as crises na saúde, na moradia e na economia vigorem com mais força entre os vulneráveis.

Outro aspecto importante foi a grande migração ocorrida nas décadas de 60 e 70, a qual atraiu milhões de pessoas aos centros urbanos de modo que as cidades não suportaram tamanho contingente, inviabilizando a aplicação de uma vida digna. Nesse ponto, Amauri Meireles afirma: 
Com o milagre brasileiro-ocorrido entre 1969 e 1973, um período marcado, sem dúvida, por extraordinário crescimento econômico, ocorreu um êxodo rural muito forte. Pela primeira vez no Brasil, em 1972 a população urbana voltou a ultrapassar a população rural, provocando redução de produtores no campo e aumento de consumidores na cidade grande, que não estava preparada para essa migração. (MEIRELES, 2019, p.199).

Assim, diferentemente do sertanejo que peregrinava em regiões próximas do grande sertão brasileiro das décadas de 30 e 40, tentando fugir do castigo das secas, conforme demonstrado no romance Vidas secas de Graciliano Ramos, o migrante, da década de 70, principalmente das regiões Nordeste e Norte, buscava nas grandes metrópoles oportunidade de emprego e de uma vida melhor. (RAMOS, 2019)

Evidentemente, que a migração não é a causa fundamental do flagelo social, pelo contrário, contribuiu e muito para a expansão econômica brasileira. contudo, a dinâmica das metrópoles mudou, de modo que surgiram moradias precárias com a consequente expansão das favelas, e não muito incomum, também aparecem famílias inteiras de migrantes que passam a viver na rua à espera de oportunidade.

Soma-se a isso, outras características que destacam o perfil heterogêneo da população de rua, uma vez que as causas individuais que levam uma pessoa viver dessa forma são diversas, como drogas, problemas familiares, problemas psicológicos e desemprego.

O caráter homogêneo do morador de rua começou a se dissipar quando a maioria da população brasileira deixou de ser rural para se transformar urbana. Essa transição também mudou as características e as demandas daqueles que, por razões diversas, depararam-se com a realidade da marginalização.

Dessa forma, pensar nos moradores de rua como um grupo homogêneo é equivocado. São pessoas diferentes, com realidades dissonantes, demandando ações de integração social diferenciadas.

\section{REINTEGRAÇÃO DE POSSE EM TEMPOS DE PANDEMIA}

Uma das principais desumanidades em desfavor da população de rua é a reintegração de posse realizadas em plena pandemia. Embora seja ilegal ocupar espaços particulares, deve-se sempre zelar pelos princípios da razoabilidade e proporcionalidade presentes no Direito pátrio afim de não maximizar o sofrimento humano.

No entanto, desprezando a pior crise de saúde pública da história, em todo o Brasil, é noticiado que continuam as reintegrações, prevalecendo o direito do autor sobre a necessidade de abrigo em momentos gravosos, conforme demonstra reportagem do Estado de Minas Gerais (EM plena..., 2020)

Atualmente, debate-se se o direito à propriedade, consagrado na constituição, deve prevalecer a despeito de qualquer outro direito, uma vez que, conforme pregam o capitalismo e o liberalismo, o homem não deve ser privado daquilo que lhe é natural. 
John Locke, por exemplo, via a propriedade como um estado de natureza, um direito individual, em que o ser humano, através de sua habilidade, constrói para si atributos que não devem lhe ser tirados. (ALMEIDA, 2016)

Por sua vez, Rousseau entendia a propriedade privada como a origem da desigualdade, levando o homem a competir entre si, em um ciclo constante de injustiça. (ROUSSEAU, 2011)

Pondera-se que é necessário evitar os extremos, de modo que é equivocado conceber a propriedade como direito absoluto. Por outro lado, deve-se resguardar esse direito levando em conta o interesse público, principalmente das pessoas vulneráveis.

O Ministro do Supremo Tribunal Federal, Alexandre de Moraes, tem o mesmo pensamento ao afirmar que

A referência constitucional à função social como elemento estrutural da definição do direito à propriedade privada e da limitação legal de seu conteúdo demonstra a substituição de uma concepção abstrata de âmbito meramente subjetivo de livre domínio e disposição da propriedade por uma concepção social de propriedade privada , reforçada pela existência de um conjunto de obrigações para com os interesses da coletividade, visando também a finalidade ou utilidade social que cada categoria de bens objeto de domínio deve cumprir.(MORAES, 2021.p. 219)

Assim, constitucionalmente, a propriedade deve cumprir sua função social, beneficiando a coletividade. Porém, esse conceito perde sua finalidade a partir do instante em que milhares de pessoas são expulsas e despojadas quando mais necessitam de amparo.

Sobre essa finalidade, fala Tartuce:

Pode-se definir a propriedade como o direito que alguém possui em relação a um bem determinado. Trata-se de um direito fundamental, protegido no artigo $5^{\circ}$. inciso XXII, da Constituição Federal, mas que deve sempre atender a uma função social, em prol de toda coletividade. A propriedade é preenchida a partir dos atributos que constam do código civil de 2002, sem perder de vista outros direitos, sobretudo aqueles com substrato constitucional (TARTUCE, 2020. p. 870)

Assim é que se questiona a legitimidade de se fazer desapropriações em tempos de pandemia, momento em que as pessoas mais vulneráveis necessitam de um lugar de acolhimento. Deve-se observar que o direito à propriedade não pode ferir outro direito básico, isto é, o direito à moradia, conforme ensina o Padre Júlio Lancelot, em artigo publicado na Folha de São Paulo: “As pessoas são expulsas das regiões centrais, reprimidas e tratadas com repressão e violência. A propriedade e a especulação ferem e matam". (FOLHA DE SÃO PAULO, 2020)

Salienta-se que reintegração de posse é a ação movida pelo real proprietário de um bem esbulhado ou turbado cuja posse está em mãos de terceiro. Ela é apre- 
sentada conforme o rito especial do código de processo civil brasileiro de 2015 prescrito a partir do artigo 560.

No contexto atual, tem-se travado batalhas judiciais em que muitos desses processos vêm sendo suspensos, entendendo os julgadores que o momento exige equilíbrio e humanidade, conforme decisão do tribunal de justiça do Distrito Federal, no agravo de instrumento 0730117-63.2020.8.07.0000, de relatoria do Ministro Rômulo De Araújo Mendes. Nesse caso, entendeu o Magistrado que a situação atual requer cautela e equilíbrio, fazendo valer o princípio da dignidade da pessoa humana ao afirmar que:

Deve sopesar a atual situação em que o país se encontra em razão da pandemia do coronavírus, o que implica uma análise peculiar quanto ao direito à moradia e as consequências de se retirar da posse o agravado, ainda que se trate de área pública. (TJDFT,2020)

Não se trata, portanto, de mero conflito entre normas, e sim de se buscar a deliberação mais justa, considerando o quadro pandêmico que o país vive. O legítimo proprietário, o qual paga seus impostos, tem direito de usar, gozar e dispor do bem. Por sua vez, o critério humanitário precisa prevalecer quando se fala em deixar pessoas, que já não possuem quase nada, sem a dignidade de um teto.

É necessário, para fazer valer os princípios citados, ir de encontro aos interesses de grandes grupos econômicos-poderosos que não medem esforços para que seus objetivos sejam contemplados a despeito da miséria alheia. Por isso, as entidades civis e o poder público devem estar atentos para cumprir o que diz a constituição.

\section{CRACOLÂNDIA E A POPULAÇÃO DE RUA}

A cracolândia, localizada na região central de São Paulo, é conhecida por abrigar uma população em situação de rua, usuária de drogas, especialmente crack. Esse espaço já foi palco de várias ações do poder público, no intuito de desocupar o local, através de operações policiais, muitas delas acabando com repressão e violência.

Essas tentativas do poder público de resolver o problema da região geram polêmicas, tendo em vista o desrespeito aos direitos humanos em muitas dessas intervenções, principalmente pelo uso desproporcional da força.

Segundo o site G1, nos últimos meses, ocorreram 12 flagrantes de ações da GCM com agressões, uso de bombas e spray de pimenta (G1, 2021). Na mesma matéria é reportado o fato em que dois moradores de rua sofreram com disparos de bala de borracha, sendo que um deles perdeu o olho em ação da guarda metropolitana na região.

Essas ações violentas levaram o Ministério Público a entrar com ação civil pública contra a prefeitura de São Paulo. Na petição inicial o MP afirma que: 
A complexidade social, sanitária, econômica, urbanística, política e cultural da denominada "Cracolândia" desafia os administradores públicos, que não conseguem, decorridos os anos, articular eficientes políticas públicas de saúde e assistência social. (MP/SP, 2021, p. 3)

Na mesma ação (Processo número 1033071-79.2021.8.26.0053), a defensoria pública requereu ingresso como assistente litisconsorcial, sob o argumento de que as ações da guarda metropolitana na cracolândia atentam contra a constituição, sintetizando a tese do Ministério público:

Com efeito, em breve síntese, o Ministério Público do estado de São Paulo ajuizou ação civil pública em face da Prefeitura de São Paulo, argumentando que a atuação da Guarda Civil Metropolitana do município de São Paulo é manifestamente afrontosa ao desenho constitucional dessa instituição. Sustenta, ademais, que a atuação da Guarda Municipal em áreas urbanas com cenas de uso de drogas acarreta grave violação de direitos fundamentais de pessoas que fazem uso problemático de drogas, que estão em situação de rua e de cidadãos e cidadãs em geral. Por isso, postula, ao final, o controle judicial da atuação da Guarda Civil Metropolitana do município de São Paulo. (DEFENSORIA DE PÚBLICA/SP, 2021, p 1068)

Como visto, a defensoria e o Ministério Público afirmam que a violência empenhada pelas forças de segurança viola direitos fundamentais das pessoas em situação de rua, uma vez que a repressão não leva em conta a situação de dependência química dos vulneráveis.

Outro ponto muito discutido é a dispersão dessas pessoas, o que ocasiona outros pontos de concentração de usuários de drogas, gerando pequenas cracolândias 'pela cidade. Assim, o uso da força nesse espaço não surte o efeito esperado, uma vez que é notório a complexidade da população que ali habita diariamente.

Nesse sentido, deslocar compulsoriamente as pessoas não é medida eficiente, conforme aponta levantamento recente da UNIFESP, que estuda o grau de vulnerabilidade dos dessa população no que se refere a questões sociodemográficas, situação de saúde, uso de drogas e tratamento adequado aos dependentes.

Nessa recente pesquisa, que busca traçar a dinâmica da cracolândia, realizada pela Unidade de Pesquisas de Álcool e Drogas (UNIAD), da Universidade Federal de São Paulo (UNIFESP), foi apontado que 42\% dos usuários de drogas vivem nas ruas há pelo menos 5 anos, revelando alto grau de vulnerabilidade (UNIAD,2020).

Dessa forma, caso sejam expulsos da cracolândia, essas pessoas buscarão refúgio em outros locais da cidade, pois o problema não é apenas socio geográfico, mas também é uma questão de saúde pública.

\section{EXCLUSÃO E DIREITO À CIDADANIA.}

Segundo o IPEA, existem 220 mil pessoas morando na rua no Brasil atualmente, um crescimento de 140 por cento em relação a 2012. Ainda segundo 
a entidade, a maioria vive nas grandes cidades dos sudestes, nordeste e sul do país. (IPEA, 2020)

Assim, a população de rua tem aumentado nos últimos anos no Brasil, desafiando os governantes dos grandes centros urbanos a encontrar soluções capazes de conter esse avanço, bem como a responder de forma humanitária às principais necessidades da população de rua.

Nesse cenário, observa-se que existem centenas de campanhas pelo país, tratando de diferentes temas como saúde, sexualidade e educação, porém são raras as campanhas de inclusão e socialização em prol dos moradores de rua.

Assim, ele não sofre somente pela falta de moradia e pela constante violência, mas também pela exclusão social. Por todo país multiplicam-se relatos desumanos, principalmente a expulsão de marginalizados dos espaços públicos, seja de forma direta ou indireta, como fez a prefeitura de São Paulo ao colocar pedras em viadutos com o intuito de dificultar o acesso dos miseráveis a esses locais.

Dessa forma, percebe-se o processo de censura espacial nos projetos arquitetônicos por meio de construções que hostiliza o morador de rua, objetivando dificultar o seu acesso aos locais públicos e privados.

Devido a repercussão negativa e o protesto de personalidades que lidam com os vulneráveis, tramita na câmara um texto que proíbe arquitetura hostil à população de rua. (SENADO FEDERAL, 2021)

O projeto é uma forma de coibir a administração pública de implementar, no plano diretor municipal, a execução de obras que impossibilitem o trânsito de pessoas marginalizadas.

Apesar disso, a exclusão passa despercebida, uma vez que esse público é invisível, afinal pouco consome, não frequenta lugares sofisticados, em suma: não faz o PIB crescer. Para muitos apenas polui as cidades com seu traje e modo.

Não é incomum personalidades pedirem a retirada dos moradores de rua de locais públicos e particulares. Essas atitudes alimentam a sensação de censura social, dificultando a interação e a possibilidade dessas pessoas ascenderem.

Assim, pode-se afirmar que preconceito e exclusão estão interligados, uma vez que o primeiro lastreia sentimentos ruins para com os marginalizados, desencadeando uma série de consequências no tecido social que vai da falta de oportunidades a discriminação e violência, conforme aponta ementa do tribunal de justiça do Distrito federal.

HABEAS CORPUS. HOMICÍDIO QULIFICADO CONSUMADO. HOMICÍDIO TENTADO QUALIFICADO (TRÊS VEZES). CORRUPÇÃO DE MENORES. PRISÃO PREVENTIVA. LIBERDADE PROVISÓRIA NEGADA. INDÍCIOS DE AUTORIA. PROVA DA MATERIALIDADE. FUMUS COMISSI DELICTI VERIFICADO. PRESSUPOSTO PREENCHIDO. FUNDAMENTO. ART. 312, CPP. MODUS OPERANDI. GRAVIDADE CONCRETA. PERICULOSIDADE DO PACIENTE. PACIENTE QUE ATEOU FOGO EM MORADOR DE RUA ENQUANTO DORMIA. GARANTIA DA ORDEM PÚBLICA. FUNDAMENTAÇÃO ESCORREITA. REQUISITO. PENA PRIVATIVA DE LIBERDADE 
MÁXIMA SUPERIOR A 4 ANOS. PREDICADOS PESSOAIS. IRRELEVÂNCIA. ORDEM DENEGADA. (TJ/DF. Segunda turma recursal. Habeas corpus 20130020249389HBC Relator

Desembargador SILVÂNIO BARBOSA DOS SANTOS. Acórdão N 733785. Julgado em 07/11/2013. Publicado em 13/11/2013. Grifo nosso.)

Assim, ninguém ateia fogo em outrem, com plena vontade e capacidade de raciocínio, sem antes está permeado de ódio e preconceito, conforme julgado supracitado. Dessa forma, a falta de inclusão agrava a situação dos flagelados, seja pelo ciclo de miséria intransponível, seja pela percepção discriminatória de alguns grupos na sociedade.

Essa exclusão gera a percepção equivocada de que o morador de rua não é cidadão, e nessa condição não deve ser respeitado enquanto sujeito de direitos.

O tema da cidadania foi debatido à exaustão na Grécia antiga em Platão e Aristóteles. Este último afirma que o Autêntico cidadão é aquele que se submete às leis, conforme descrito no livro a política. (ARISTÓTELES,2009)

Na contemporaneidade, o que torna efetivo o direito à cidadania é a participação do indivíduo nas questões centrais de uma nação, tais como integração política, social e civil. Dessa forma, garantir direitos fundamentais ao morador de rua passa pelo seu envolvimento pleno à vida em sociedade.

Não há que se falar em interação social enquanto programas voltados a minorias não forem institucionalizados, objetivando a redução da pobreza e da discriminação. Com isso, será possível a grupos desfavorecidos não só questionar o modo como as políticas públicas são realizadas, mas também decidir quem administra tais recursos.

Ressalta-se a necessidade de preservar a dignidade humana para que certos direitos possam ser concretizados. Assim, falta à população de rua o mínimo para a prática da cidadania, tendo em vista sua precária alimentação, a exposição à violência das grandes cidades e as intempéries da falta de moradia.

Não pode, portanto, o Estado se furtar de sua obrigação jurisdicional de preservar direitos dos mais vulneráveis, não fomentando a violência e a exclusão, conforme julgado hodierno, o qual comprova a ação violenta de agentes públicos.

EMENTA: APELAÇÃO CÍVEL - AÇÃO POPULAR - APREENSÃO DE PERTENCES PESSOAIS E DOCUMENTOS DA POPULAÇÃO EM SITUAÇÃO DE RUA - VIOLAÇÃO À MORALIDADE ADMINISTRATIVA - DIGNIDADE DA PESSOA HUMANA - DIREITO À IGUALDADE E À PROPRIEDADE - VIOLAÇÃO - PROCEDÊNCIA DO PEDIDO ÔNUS DA PROVA - SENTENÇA MANTIDA. 1. Nos termos da Lei $n^{\circ}$ $4.717 / 1965$, qualquer cidadão é parte legítima para ajuizar ação popular visando anular ou declarar a nulidade de atos lesivos ao patrimônio público das pessoas jurídicas elencadas no caput do seu artigo $1^{\circ}$, entendendo-se como patrimônio público os bens e direitos de valor econômico, artístico, estético, histórico ou turístico, ao que se acresce que a CR/1988 passou a admitir o cabimento da ação popular também para anular atos que ofendam a moralidade administrativa ou o meio am- 
biente. 2. A retirada de documentos de identificação e objetos pessoais dos moradores em situação de rua, sem justa causa e a lavratura do auto correspondente, configura violação aos direitos dessa população altamente vulnerável, diminuindo sua possibilidade de sobrevivência, com o mínimo de dignidade, infringindo demais disso os direitos fundamentais da igualdade e propriedade (artigo $5^{\circ}$ da CR/88). 3. Desincumbindo-se o autor de seu ônus probatório, demonstrando a conduta abusiva praticada pelos agentes públicos, ao contrário dos réus, deve ser mantida a sentença de procedência, não podendo o poder de polícia fundado na supremacia do interesse público justificar a prática de excessos, contrariando a dignidade da pessoa humana. 4. Primeiro recurso não conhecido. Segundo recurso não provido. (TJMG - Apelação Cível 1.0024.12.135523-4/004, Relator(a): Des.(a) Teresa Cristina da Cunha Peixoto, 8 a CÂMARA CÍVEL, julgamento em 25/04/2019, publicação da súmula em 14/05/2019. Grifo nosso)

Pode-se afirmar que não tolerar essas barbaridades é fundamental para resgatar o morador de rua de sua posição social, sendo essa resistência ato de cidadania em tempos tão complexos, não restando dúvida de que para o cidadão usufruir e exercer seus direitos é preciso segurança, liberdade, direito à propriedade, e a possibilidade de resistir a todas as formas de opressão, conforme prescreve o artigo $2^{a}$ da Declaração dos Direitos do Homem e do Cidadão, de 1789.

\section{CONSIDERAÇÕES FINAIS}

A população de rua, no que se refere aos direitos fundamentais, é desrespeitada diariamente pela falta de condições dignas de sobrevivência. Assim estão ausentes para esse grupo alimento, trabalho, abrigo, saúde e segurança, questões amplamente previstas no artigo 5 da Constituição.

Ainda, conclui-se que a proteção desses direitos precisa ir além do pragmatismo e do positivismo, sendo necessárias ações concretas, como observado em alguns julgados, pelos quais foram assegurados direito de posse e de respeito à cidadania.

Dessa forma, embora se reconheça a complexidade dessa vulnerabilidade social, quer seja pelo seu caráter heterogêneo, quer pelo seu desenvolvimento histórico, existem instrumentos pelos quais se possam minorar o sofrimento humano, como a organização da sociedade civil e a ação conjunta dos três poderes.

Por isso, infere-se que os atores públicos possuem um papel fundamental para garantir a efetivação dos direitos dos vulneráveis, uma vez que o Estado, através de uma legislação inclusiva, é quem detém os mecanismos capazes de concretizar a aplicação da dignidade da pessoa humana. 


\section{REFERENCIAS}

ALMEIDA, Guilherme. Curso de filosofia do direito. 12a edição. São Paulo: Atlas, 2016

ARISTÓTELES. A política. 5a ed. São Paulo: Martim Claret,2009.

Brasil tem $2^{\mathrm{a}}$ maior concentração de renda do mundo, diz relatório da ONU. Portal g1. São Paulo,2019. Disponível em < https://g1.globo.com/mundo/noticia/2019/12/09/ brasil-tem-segunda-maior-concentracao-de-renda-do-mundo-diz-relatorio-da-onu.ght$\underline{\mathrm{ml}>\text { Acesso }} 28$ fev. 2021

BRASIL, CONSTITUIÇÃO DA REPÚBLICA FEDERATIVA DO BRASIL DE 1988, DOS DIREITOS E GARANTIAS FUNDAMENTAIS. Brasil, 2020. Disponível em: < http:// www.planalto.gov.br/ccivil_03/constituicao/constituicao.htm> Acesso em: 20 out. 2020

BRASIL, RESOLUÇÃO N. 02/2015. CÓDIGO DE ÉTICA E DISCIPLINA DA OAB. Brasil, 2015. Disponível < https://www.oab.org.br/publicacoes/AbrirPDF>> Acesso em: 20 de out. de 2020

COSTA, Ana Paula. População em situação de rua: contextualização e caracterização. Revista Virtual Textos \& Contextos, n ${ }^{\circ}$ 4, dez. 2005

Disponívelem<https://www5.tjmg.jus.br/jurisprudencia/pesquisaNumeroCNJEspelhoAcordao.do?numeroRegistro=1\&totalLinhas=1\&linhasPorPagina=10\&nume-

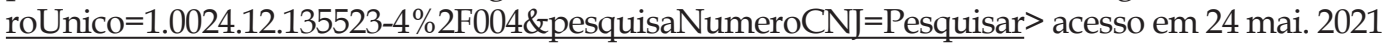

DECLARAÇÃO DOS DIREITOS DO HOMEM E DO CIDADÃO, 1789. Universidade de São Paulo: Biblioteca Virtual de Direitos Humanos, 2015. Disponível em: <http:/ /www. direitoshumanos.usp.br/index.php/Documentos-anteriores-\% C3\% A0-cria\% C3\% A7\%C3\% A3o-da-Sociedade-das-Na\% C3\% A7\% C3\%B5es-at\% C3\% A9-1919/declaracao-de-direitos-do-homem-e-do-cidadao-1789.html>. Acesso em: 24 mai. 2021

DISTRITO FEDERAL. Tribunal de justiça do distrito federal. Acórdão No 1307890. Agravante (s) ministério público do distrito federal e dos territórios agravado (s) Carlos José moreira da silva relator desembargador Rômulo de Araújo mendes. Agravo de instrumento 0730117-63.2020.8.07.0000, julgado em 02/12/2020. Publicado em Publicado em 17/12/2020<Disponível em <https:// pesquisajuris.tjdft.jus.br/IndexadorAcordaosweb/ sistj?visaoId=tjdf.sistj. acordaoeletronico.buscaindexada.apresentacao.VisaoBuscaAcordao\&nomeDaPagina=buscaLivre2\&buscaPorQuery=1\&baseSelecionada=BASE_ACORDAOS\&filtroAcordaosPublicos=false\&camposSelecionados $=[$ ESPELHO $\&$ \&argumentoDePesquisa $=07301176320208070000 \&$ numero $=\&$ tipoDeRelator $=$ TODOS\&dataFim $=$ \&indexacao $=\&$ ramoJuridico $=\&$ baseDados $=[$ TURMAS_RECURSAIS, $\% 20$ BASE_ACORDAOS_IDR,\%20BASE_TEMAS,\%20BASE_ACORDAOS,\%20BASE_INFORMATIVOS]\&tipoDeNumero=NumAcordao\&tipoDeData=DataPublicacao\&ementa=\&filtroSegredoDeJustica $=$ false\&desembargador $=\&$ dataInicio=\&legislacao=\&orgaoJulgador=\&numeroDaPaginaAtual=1\&quantidadeDeRegistros=20\&totalHits=1>Acesso em 12 mar. 2021.

DISTRITO FEDERAL. Tribunal de justiça. Acórdão 733785, 20130020249389HBC, impetrante Fernando Carneiro Brasil. Paciente Wesley lima da silva. Relator: Silvânia Barbosa dos santos, $2^{\text {a }}$ Turma Criminal, data de julgamento: 7/11/2013, publicado no DJE: 
13/11/2013. Disponivél em < https://pesquisajuris.tjdft.jus.br/indexadoracordaosweb/ sistj?Visaoid=tjdf.sistj.acordaoeletronico.buscaindexada.apresentacao.visaobuscaacordaoget\&numerododocumento=733785 > acesso em 24 mai. 2021.

EM plena pandemia de COVID-19, tensão marca reintegração de posse no Sul de Minas. O ESTADO DE MINAS GERAIS. <Disponível em https://www.em.com.br/app/noticia/gerais/2020/08/12/interna_gerais,1175396/em-plena-pandemia-covid-tensao-marca-reintegracao-posse-sul-de-minas.shtml> acesso em 10 mar. 2021.

ESTUDO traça perfil de usuários e estima que cracolândia movimenta $\mathrm{R} \$ 10$ milhões por mês. Disponível https://www.uniad.org.br/noticias/levantamentos-e-pesquisas/estudo-traca-perfil-de-usuarios-e-estima-que-cracolandia-movimenta-r10-milhoes-por-mes/ Acesso em: 27 jul. 2021

FAUSTO, Boris. História concisa do Brasil.3ª ed. São Paulo: Edusp,2018.

FREYRE, Gilberto. Casa-grande e Senzala.51ª ed. São Paulo: Global,2006.

G1. Polícia realiza operação contra o tráfico de drogas na Cracolândia. Disponível em <https://g1.globo.com/sp/sao-paulo/noticia/2021/06/18/policia-realiza-operacao-contra-o-trafico-de-drogas-na-cracolandia.ghtml> Acesso em 27 jul. 2021

IPEA. População em situação de rua cresce e fica mais exposta à Covid-19. São Paulo,12/06/2020. Disponível em: <https://www.ipea.gov.br/portal/index.php?option=com_content\&view=article\&id=35811 > Acesso em: 20 out. 2020.

LENZA, Pedro. Direito constitucional esquematizado. 16 ed. São Paulo: Saraiva, 2012.

MEIRELES, Amauri. O fenômeno da população de rua. In: GRINOVER, Ada Pellegrini et al (org.). Direitos fundamentais dos moradores de rua. 2 ed. Belo Horizonte: D’́plácido, 2019, p.199-220.

MINAS GERAIS. Tribunal de justiça. Apelação cível 10024121355234004. $8^{a}$ câmara cível. Apelante: município de belo horizonte - apelado (a)(s): André novais machado. Desa. Teresa Cristina da cunha Peixoto. Belo Horizonte, MG, 25/04/2019, publicado 14/05/2019. Disponível em:

<https://www5.tjmg.jus.br/jurisprudencia/pesquisaNumeroCNJEspelhoAcordao.do? numeroRegistro $=1$ \&totalLinhas $=1$ \&linhasPorPagina $=10$ \&numeroUnico=1.0024.12.135523-4\%2F004\&pesquisaNumeroCNJ=Pesquisar $>$ acesso em: 14 de jun de 2021

MINISTÉRIO Público do Distrito Federal e Territórios - MPDFT. Moradores em situação de rua. Pag 4. MPDFT: 2018. Disponível em: < https://mpdft.mp.br/portal/pdf/imprensa/cartilhas/cartilha_direitos_das_pessoas_situacao_de_rua_mpdft.pdf > Acesso em: 20 out. 2020.

MORAES, Alexandre de. Direitos humanos fundamentais. Teoria geral. Comentários aos artigos $1^{\circ}$ a $5^{\circ}$ da república federativa do Brasil. 12 ed. São Paulo: Atlas, 2021. 
PADRE LANCELOTE, Júlio. A população e a rua. Folha de S.Paulo, São Paulo, 26 de set. de 2020. Disponível em: < https://www1.folha.uol.com.br/opiniao/2020/09/a-populacao-e-a-rua.shtml >. Acesso em: 20 out. 2020.

PLATÃO. A República. São Paulo: Martim Claret, 2007.

RAMOS, Graciliano. Vidas secas. 150 ed. São Paulo: Record, 2019.

RIBEIRO, Darcy. O Povo Brasileiro: a formação e o sentido do Brasil. São Paulo: Companhia das letras, 2006.

ROUSSEAU, Jean-Jacques. Do contrato social. São Paulo: Martin Claret, 2011.

SÃO PAULO. Tribunal de Justiça. Ação civil pública. Processo nº 1033071-79.2021.8.26.0053. Requerente: Ministério Público do Estado de São Paulo. Requerido: Prefeitura de São Paulo. Disponível em

<https:/ / esaj.tjsp.jus.br/pastadigital/abrirPastaProcessoDigital.do?nuProces$\mathrm{so}=103307179.2021 .8 .26 .0053 \& \mathrm{cdProcesso}=1 \mathrm{H} 000 \mathrm{JZ} 9 \mathrm{P} 0000 \& \mathrm{cdForo}=53 \&$ baseIndice $=\mathrm{IN}-$ DDS\&nmAlias $=$ PG5JM\&tpOrigem $=2 \&$ flOrigem $=$ P\&cdServico $=190101 \&$ acessibilida$\mathrm{de}=$ false\&ticket=7\% 2B1pM0KjkD8ToeFBIZkMB8o7DbaRQP0ciU9v3jTQY9DeBxdKdyk\%2FYfy\% 2FDhiHd \% 2BmJovlZ9YVn1wWv85UNOn1an2CClIGJ4TaILNbJg1\%2FleyaiUEcHmbHPc5dZDXQxN9dhSSa \%2FaaSwdKVZgUo3VY5mVJXav8I0xIIxnkJKU8XBAhT1vZtkMsMoTCfZC2FQSIsdpu5I0oERzG8vZnF6zX\%2B3tUL81nfhQe\%2FCT7MZM4YD4xJAiwSG8E4VI2hXBpD4DGoZBRcr3B2VjNyFT8loyDcfiVzfeXyiKKtZpGxBKXxfzJGCc09gdP81WvZEOnQjSoQloF42NxpYerKKixDKBvyJc6emXTQP\%2B2T7rWXmfMxa3UOxtCssT5nsZni5X6brpgTK6iHM5a3dTWzbuI\%2BllnuvTg\%3D\%3D> Acesso em 27 jul. 2021.

TADEU, Fernando. Efetivação de direitos da população em situação de rua como pressuposto básico da dignidade da pessoa humana. In: GRINOVER, Ada Pellegrini et al (org.). Direitos fundamentais dos moradores de rua. $2^{a}$ ed. Belo Horizonte: D’́plácido, 2019, p.359-374.

TAVARES, André Ramos. Curso de direito constitucional. 18 ed. São Paulo: Saraiva,2020.

VAI à Câmara texto que proíbe arquitetura hostil à população de rua em espaço público. Senado Federal. Disponível em: < https://www12.senado.leg.br/noticias/materias/2021/03/31/vai-a-camara-texto-que-proibe-arquitetura-hostil-a-populacao-de-rua-em-espaco-publico-> acesso 20 abr. 2021. 